\title{
An Ethnobotanical Study of Traditional Knowledge and Uses of Medicinal Wild Plants among the Marakwet Community in Kenya
}

\author{
Bernard K. Wanjohi $\mathbb{D}^{1},{ }^{1}$ Vincent Sudoi, ${ }^{2}$ Elizabeth W. Njenga, ${ }^{3}$ and Wilson K. Kipkore ${ }^{4}$ \\ ${ }^{1}$ Department of Wildlife Management, University of Eldoret, P.O. Box 1125-30100, Eldoret, Kenya \\ ${ }^{2}$ School of Environmental Studies, Department of Environmental Biology, University of Eldoret, P.O. Box 1125-30100, \\ Eldoret, Kenya \\ ${ }^{3}$ Department of Biological Sciences, University of Eldoret, P.O. Box 1125-30100, Eldoret, Kenya \\ ${ }^{4}$ Department of Forestry and Wood Sciences, University of Eldoret, P.O. Box 1125-30100, Eldoret, Kenya
}

Correspondence should be addressed to Bernard K. Wanjohi; wanjohibk@yahoo.com

Received 15 November 2019; Revised 15 January 2020; Accepted 10 February 2020; Published 30 March 2020

Academic Editor: Victor Kuete

Copyright (c) 2020 Bernard K. Wanjohi et al. This is an open access article distributed under the Creative Commons Attribution License, which permits unrestricted use, distribution, and reproduction in any medium, provided the original work is properly cited.

\begin{abstract}
Traditional plant knowledge and uses of medicinal wild plants were investigated among the Marakwet community in Kenya. Data were collected through interviews with seven traditional healers and 157 questionnaires for local community members. Traditional names of the plants by traditional healers and local community members were prepared as a checklist. Loss of traditional medicinal names of plants was ascertained with up to $60 \%$ overlapping in their nomenclature. The traditional medicinal plants treated 41 diseases within the region, of which local community members understood common ones for treating stomachache (94.8\%), diarrhea (70.7\%), chest problems (65.5\%), and typhoid (63.8\%). It was also clear that there was low knowledge index of medicinal plants by the local community members (23.6\%) based on knowledge of traditional healers. Clearly, medicinal plants for treatment of malaria, diabetes, tetanus, and pneumonia were recognized by over $40 \%$ of the local community members, while plants treating arteriosclerosis, meningitis, arthritis, trachoma, smallpox, rheumatic fever, and gout were known by less than $10 \%$ of the respondents. Among plants, the use of roots for treatment was known by over $67 \%$ of the local community members compared to fruits, bark, bulb, and flowers $(<10 \%)$. This low traditional medicinal knowledge in a community relies on the traditional medicinal plants, calling for an urgent need to document the information and perpetuate this knowledge from one generation to another. This can be achieved by collecting the information and developing a database of medicinal plants for future research and potential development of new drugs.
\end{abstract}

\section{Introduction}

The use of indigenous plants in human medicine is well documented [1]. Current knowledge on medicinal plants as a source for relief from illness dates back to the early civilization in China, India, and the Near East [2-5]. Ingredients provided by plants have a wide range of medicinal properties [6-9]. Globally, about $60-80 \%$ of the people rely on herbal medicine as for primary healthcare needs [10-12]. Subsequently, the number of plants being recommended for use as herbal medicines has increased $[13,14]$. In areas where there is perceived high cost of medical care, especially in Asia and Africa, medicinal plants have gained more recognition
[15-18]. This stems from the affordability and accessibility of traditional medicine as a source of treatment in the primary healthcare system of resource-poor communities [19-21]. Therefore, focus on the knowledge of plants used in herbal medicines has been increasing.

It is now clear that knowledge of medicinal plants use as was embedded in indigenous cultures has slowly been eroding with modernization. Thus, over the years, the decline in cultural diversity has witnessed the erosion of human knowledge on medicinal plant species, their distribution, management, and methods of extracting the useful properties of medicinal plants [22]. Knowledge of the use of medicinal plants was derived mainly through 
traditional scholarly written traditional documentation of knowledge and pharmacopoeias for doctors and institutions, as well as Traditional Medical Knowledge (TMK), among households, communities, and/or ethnic groups. Rather than legislation and/or regulation, it has been suggested that suitable strategies to enhance sustainable utilization and management of medicinal plants are focusing on local approaches involving traditional medicinal knowledge [23, 24].

Most emphasis on the respect and perpetuation of knowledge about the medicinal plants is espoused by traditional medicinal knowledge (TMK). Although there are numerous reports, published work, thesis, dissertations, books, inventories, media reports, and monographs of the diversity of medicinal plants within the tropical environment [25-30], most of these knowledge are still based purely on scientific work that totally excludes the contribution of the local community members and does not reflect TMK. Of interest is that the majority of the works so far carried out in developing countries largely focus on the inventories, utilization, and conservation of medicinal plants [21, 30-35]. Various sets of recommendations have been compiled relating to the conservation of medicinal plants, such as those associated with international conferences at Chiang Mai, Thailand, in 1988 and Bangalore, India, in 1998 (http://www. frlht-india.org). Regardless, there is little application of TMK on these inventories.

There is enormous knowledge on the use of indigenous medicinal plants in Kenya over the last decades (e.g., $[30,32,36-42])$. In light of this, therefore, there is a high expectation of enormous traditional knowledge of medicinal plant species in Kenya due to the use of diverse plant species, diversity of cultures, diverse languages, and beliefs among the different ethnic groups in Kenya. To our knowledge, there are no data regarding the traditional medicinal plant knowledge and use by several local communities in Kenya. Moreover, Kenya is one of the countries experiencing dynamic changes in cultural norms and system, which renders the traditional and local knowledge of medicinal plants to be easily forgettable as most of the indigenous traditional knowledge is transferred to the local community members orally. Therefore, the current study was conducted to assess and document the traditional and local knowledge of medicinal plants and use among traditional healers and local community members in Marakwet, Kenya.

\section{Materials and Methods}

2.1. Study Area. This study was conducted at four sites within the Embobut Region of Elgeyo Marakwet County (Kenya) between March and June 2018 (Figure 1). Embobut covers an area of 21,655 hectares. The mean annual rainfall ranges between 1100 and $1500 \mathrm{~mm}$ with two peaks in April to May and August to October [43]. Temperature ranges between $14^{\circ} \mathrm{C}$ and $25^{\circ} \mathrm{C}$ with an average of $21^{\circ} \mathrm{C}$. Soils are thin, drain freely, and have a friable texture with layers of cellular iron stone. It is a water catchment area for River Nzoia flowing into Lake Victoria. The main human activities within the study areas include livestock grazing, pastoralism, and crop and dairy farming. The main farming activities within the drainage areas include cultivation of maize (Zea mays), beans (Phaseolus vulgaris), and a variety of other noncereal crops on a smaller scale, including cabbage (Brassica oleracea var capitata) and kales (Brassica oleracea var acephala).

2.2. Population, Sample Size, and Sampling. The population was approximately 26,772 based on the KNBS (2010). From this population, about 3123 people $(11.6 \%)$ had access to the forest [43]. The sample size was determined by the formula: $n=z^{2}\left(p q / d^{2}\right)$ [44], whereby $n=$ the desired minimum sample size, $z=$ the standard normal deviation at set confidence interval, $d=$ the acceptable range of error (0.05), $p=$ the proportion of individuals accessing the forest $(11.6 \%)$, and $q=$ the proportion of individuals not accessing the forest $=1-p(88.4 \%)$. Hence, $d=0.05, p=0.116, z=1.96$ at $95 \%$ confidence level, and $q=0.884$. Thus, $n=1.96^{2}\left((0.116 * 0.884) / 0.05^{2}\right)=157$. Therefore, the desired sample size was 157 local community members from the homesteads.

A purposive was used to select the 157 respondents. In purposive sampling, the participants are selected on the basis of some specific criteria that are judged to be essential [45]. The researcher deliberately selected community members with a long period of resident in the community, which signify knowledge of the natural environment and the use of natural resources to fulfill basic needs.

2.3. Research Instruments. Data were collected through traditional healers' survey interviews and local community questionnaires. Information on identification and use of local plant species was conducted through a census with seven traditional healers who were present during the time of study. The interviews were facilitated by translators who were well-conversant of the local language (Marakwet language). Local medicinal knowledge of plants use was obtained from questionnaires administered to the local community members. The questionnaires were designed to answer the following research questions: (1) which medicinal plant species do you know in the wild? (2) what are the plants used for? and (3) which plant parts are used? The names of the plants known by the traditional healers and local community members were noted in a checklist containing the vernacular and common names and submitted to the National Museum of Kenya (NMK) for confirmation by a plant taxonomist.

2.4. Piloting. A reconnaissance visit was conducted for four days to gain basic understanding of the potential respondents for the study. After the initial visit, a week was spent preparing interviews and questionnaires for the survey and another week for training of research assistants on how to effectively administer the instruments. The services of a translator were employed where necessary. A total of 24 questionnaires were piloted. The results of the pilot were used to improve efficiency of the data collection instruments for the main survey. 

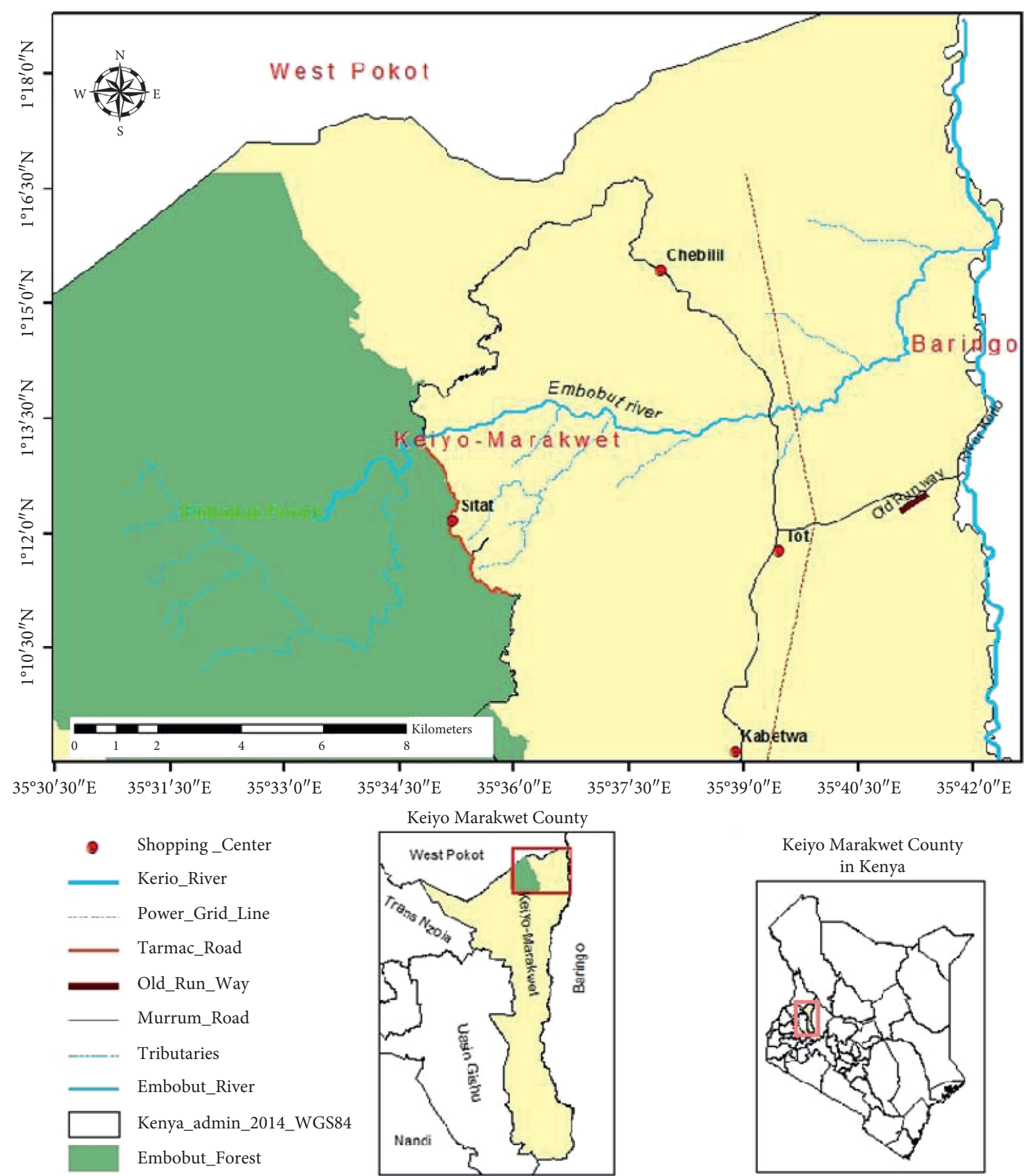

Keiyo Marakwet County in Kenya

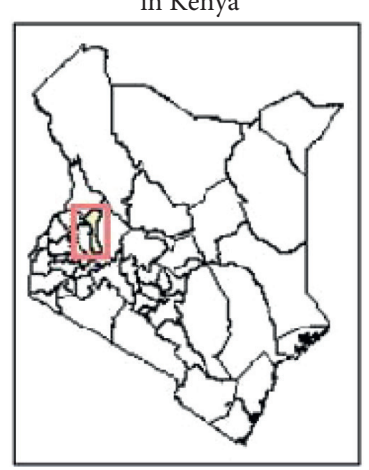

Figure 1: Map showing the location of the study area and sampling points.

2.5. Validity and Reliability of Research Instruments. To test the validity of the research instruments, a questionnaire was prepared and submitted to ethnobotany researchers for cross checking and also to assess the reliance of the content.

Reliability of the research instruments was performed during pilot through the split half technique and Cronbach alpha coefficient computed [46]. Here, the instruments were provided to a total of 24 household heads divided into 2 groups. The reliability of the items was based on the estimates of the variability of responses between the two groups.
In this study, the reliability coefficient was found to be 0.85 , which was very good for the analysis.

2.6. Data Analysis. Quantitative data were cleaned, coded, and entered into Statistical Package for Social Science (SPSS) version 23 for analysis. Descriptive and cross tabulations were carried out. On the other hand, qualitative data were analyzed through synthesized text summaries and frequency distributions. 
2.7. Ethical Considerations. This study adhered to the Ethical Standards of the University of Eldoret. Informed consent was sought and obtained before the study. Anonymity was ensured by not collecting identifying information of individual subjects. Confidentiality was ensured by not divulging the identity of the respondents or their organizations.

\section{Results}

3.1. Socioeconomic Background of the Respondents. The socioeconomic profile of the respondents is provided in Table 1 . There was gender disparity in the villages with higher number of males (71\%) than females (29\%). Most of the respondents were aged over 55 years (39\%) following those aged $46-55$ years (29\%), while those aged below 25 year were few. In Embobut, most household heads had no formal education (38\%), which was followed by those with secondary levels of education (32\%) and then primary level of education $(27 \%)$. Generally, most farmers in the study area were practicing mixed farming (58\%) followed by informal employment (16.2\%). The majority of the households had stayed in the area for over 30 years (56.9\%), followed by those who have stayed in the area for 10-19 (22.4\%), while those who have stayed in the region for less than 10 years were few in proportion.

\subsection{Traditional Medicinal Knowledge and Use of Indigenous} Medicinal Plant Species in Embobut Forest. Structured interviews with the traditional healers of the local community documented 115 indigenous medicinal plant species (Table 2; Supplementary Table 1). There was loss of traditional medicinal names of the plants with up to 69 indigenous plants (60\%) overlapping in their naming. Meanwhile, up to 53 plant species $(45.3 \%)$ had overlap in their names resulting in two names for a single plant species with another 14 (12.2\%) having an overlap of three traditional names for a local plant. The number of plant species that had a single and consensus name among the traditional healers was 46 (40\%). The local community members also identified the plant species based on the scheme developed by the traditional healers. The average identification index of the species among the locals was only $37.8 \%$. Only 3 local community members $(2.6 \%)$ positively identified all the medicinal plants. A total of $13.8 \%$ of the local community members were able to identify over $75 \%$ of the medicinal plants, while another $57.8 \%$ positively identified at least $50 \%$ of the medicinal plants. Meanwhile, up to $13 \%$ of the local community members could only identify less than $20 \%$ of the plant species.

The study established that the traditional healers had wide knowledge of the local diseases with an identification of 41 diseases occurring within the region. The knowledge of the local community members concerning the types of diseases within the Embobut Forest region is shown in Figure 2. The local identified 25 diseases within the region and disease that are known by majority of the local community members were stomachache (94.8\%), diarrhea (70.7\%), chest problems (65.5\%), and typhoid (63.8\%).
Table 1: Respondents' socioeconomic and demographic characteristics.

\begin{tabular}{|c|c|c|c|}
\hline & Characteristics & Frequency & Percent \\
\hline \multirow{3}{*}{ Gender } & Male & 82 & 70.7 \\
\hline & Female & 34 & 29.3 \\
\hline & Total & 116 & 100 \\
\hline \multirow{6}{*}{ Age } & $<25$ & 1 & 0.9 \\
\hline & $26-35$ & 11 & 9.6 \\
\hline & $36-45$ & 26 & 22.6 \\
\hline & $46-55$ & 33 & 28.7 \\
\hline & Above 55 & 45 & 39.1 \\
\hline & Total & 116 & 100 \\
\hline \multirow{5}{*}{ Education level } & None & 44 & 37.9 \\
\hline & Primary & 31 & 26.7 \\
\hline & Secondary & 37 & 31.9 \\
\hline & College & 4 & 3.4 \\
\hline & Total & 116 & 100 \\
\hline \multirow{9}{*}{ Occupation } & Crop farming & 16 & 13.7 \\
\hline & Herder (animals) & 4 & 3.4 \\
\hline & Mixed farming & 68 & 58.1 \\
\hline & Traditional herbalist & 2 & 1.7 \\
\hline & Formal employed & 3 & 2.6 \\
\hline & Business & 3 & 2.6 \\
\hline & Technicians & 2 & 1.7 \\
\hline & $\begin{array}{l}\text { Informally } \\
\text { employed }\end{array}$ & 19 & 16.2 \\
\hline & Total & 117 & 100 \\
\hline \multirow{5}{*}{ Residence } & Endo sibou & 30 & 25.9 \\
\hline & Endo kibriem & 30 & 25.9 \\
\hline & Embobut & 30 & 25.9 \\
\hline & Kapiego & 26 & 22.4 \\
\hline & Total & 116 & 100.0 \\
\hline \multirow{5}{*}{$\begin{array}{l}\text { Duration of stay } \\
\text { (years) }\end{array}$} & $<10$ & 3 & 2.6 \\
\hline & $10-19$ & 26 & 22.4 \\
\hline & $20-29$ & 21 & 18.1 \\
\hline & $>30$ & 66 & 56.9 \\
\hline & Total & 116 & 100.0 \\
\hline
\end{tabular}

Other diseases such as malaria, diabetes, and pneumonia were identified by $61.2 \%, 54.3 \%$, and $51.2 \%$ of the local community members, respectively.

The local knowledge of the numbers of indigenous medicinal plants used in management of diseases is shown in Table 3. The overall mean knowledge index of the number of medicinal plant species used in treatment of various diseases indicates a knowledge index of $23.6 \%$. The knowledge of the use of local trees for treatment of malaria, diabetes, tetanus, and pneumonia was fairly known by the majority of the local community members ( $>40 \%$ ) while plants for the treatment of arteriosclerosis, meningitis, arthritis, trachoma, smallpox, rheumatic fever, and gout were known by less than $10 \%$ of the respondents.

Information on the local medicinal knowledge of the indigenous plant parts used for treatment of diseases in the Embobut Forest region is shown in Table 4. Based on the data, the use of roots as a medicinal part of the plant known by $67 \%$ of the local community respondents. On the other hand, the use of stems, branches, and leaves in management of disease was understood by between 20 and $50 \%$ of the respondents. The knowledge of the use of the 
TABLE 2: Local identification of plant species in Embobut Forest based on TMK $(n=116)$.

\begin{tabular}{lcc}
\hline Attributes & Frequency & Percent \\
\hline Number of medicinal species identified through TMK & 115 & - \\
Number of local community respondents & 116 & 2 \\
Number of medicinal species with 4 or 5 overlapping local names among traditional healers & 14 \\
Number of medicinal species with 3 overlapping local names among traditional healers & 53 & 1.7 \\
Number of medicinal species with 2 overlapping local names among traditional healers & 46 \\
Number of medicinal species without overlapping local names among traditional healers & 37.1 & 3 \\
Mean TMK knowledge index (\%) & 16.0 \\
Members of local community who identified 100\% of medicinal use & 37.8 \\
Members of local community who identified $\geq 75 \%$ of medicinal use & 2.6 \\
Members of local community who identified $\geq 50 \%$ of medicinal use & 13.8 \\
Members of local community who identified $\leq 20 \%$ of medicinal use & 57.8 \\
\hline
\end{tabular}

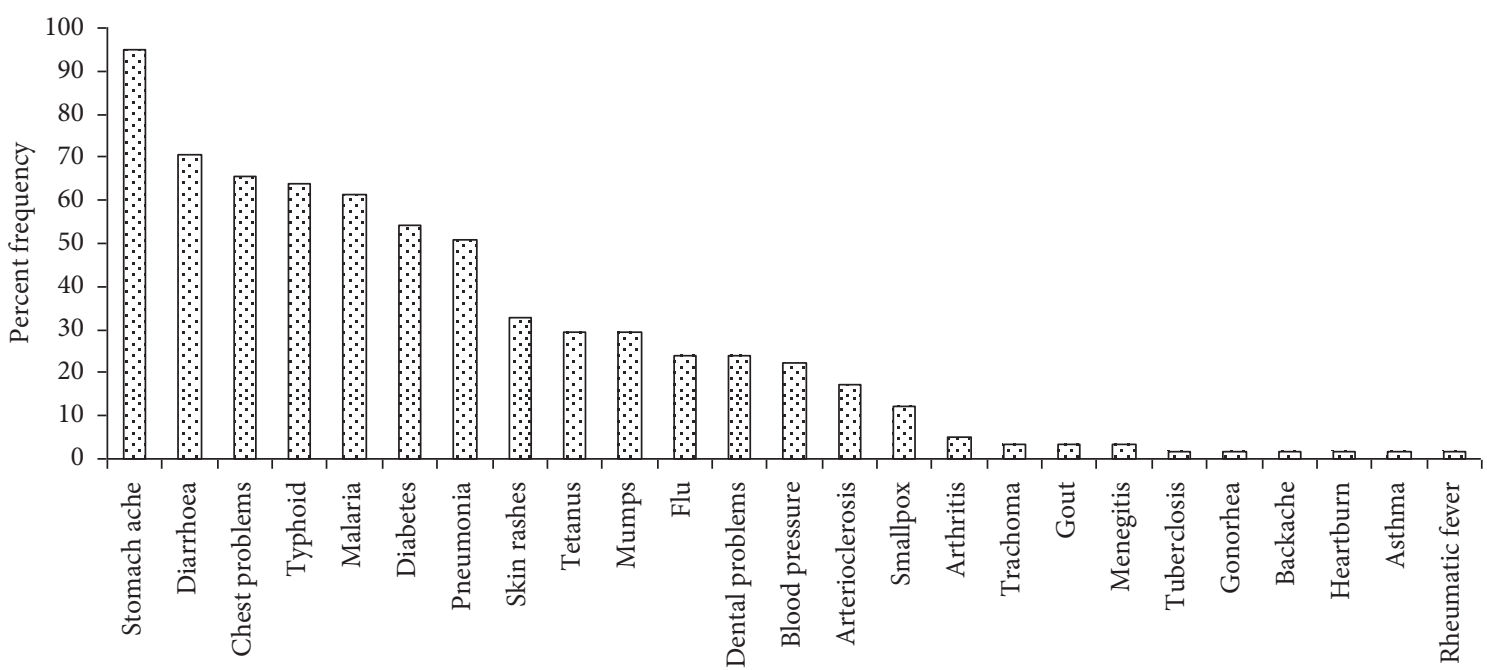

Figure 2: Local knowledge of the types of diseases within the Embobut Forest region $(n=116)$.

remaining parts of the plants, viz, fruits, bark, bulb, and flowers were known by less than $10 \%$ of the local community members.

\section{Discussion}

In the current study, a total of 115 medicinal plant species in 27 families were used by traditional healers in the Marakwet ethnic community of Kenya. A previous study in the same region yielded a total of 111 medicinal plants used by the local community [39]. Knowledge of the number of medicinal plants in the current study was higher than that in Samburu area [47] as well as in Baringo County [48]. Based on the documented medicinal plant used, it is suggested that there may be more medicinal plants used by the Marakwet or the knowledge of the traditional plants being used for medicinal purpose is much better than in other areas or both. However, during the study, there was also evidence of possible loss of traditional medicinal knowledge as attested by the traditional healers who expressed diverse knowledge on naming of medicinal plants. Indeed, the study established an overlap in naming of up to $60 \%$ of the medicinal plants by traditional healers, where $1.7 \%$ of the identified species had up to 4-5 names that overlapped in their local nomenclature while up to $45.3 \%$ overlapped in their names and $12.2 \%$ overlapped with upto three traditional names. Only $40 \%$ of the species had a single and consensus name among the traditional healers. Overlapping of traditional names of trees is one way that has been established to result in the loss of traditional medicinal knowledge [49-53]. It is possible that loss of traditional medicinal knowledge may be attributed to the nature of transmission of traditional medicinal knowledge from one generation to the other, which has often been orally performed.

During the study, the computed medicinal plant identification index was $37 \%$ indicating that out of every 100 plant species, the locals managed to identify positively only 37 . It was even more surprising that only $2.6 \%$ of the local community members managed to identify all the medicinal plants, while up to $13 \%$ of the local community members could only identify less than $20 \%$ of the plant species. These results suggest an erosion of traditional medicinal knowledge, which concurs with other studies elsewhere [54, 55].

Stomach ache, malaria, diarrhea, chest problems, and typhoid $(63.8 \%)$ were more prevalent diseases identified by the local community members. Other diseases such as malaria, diabetes, and pneumonia were identified by $61.2 \%$, $54.3 \%$, and $51.2 \%$ of the local community members, respectively. The knowledge index of medicinal plant species for treating various diseases was low among the local 
TABLE 3: Local knowledge of the numbers of indigenous plants used in management of diseases using the indigenous plant species $(n=116)$.

\begin{tabular}{|c|c|c|}
\hline & Number of plants used (traditional healers) & Weighted knowledge of use index (\%) \\
\hline Disease managed & & Frequency \\
\hline Stomach ache & 44 & 33.5 \\
\hline Diarrhea & 46 & 24.5 \\
\hline Chest problems & 12 & 32.1 \\
\hline Typhoid & 29 & 22.8 \\
\hline Malaria & 35 & 76.4 \\
\hline Diabetes & 25 & 61.2 \\
\hline Pneumonia & 13 & 44.5 \\
\hline Skin rashes & 19 & 34.5 \\
\hline Tetanus & 19 & 45.6 \\
\hline Mumps & 18 & 43.6 \\
\hline Flu & 16 & 32.4 \\
\hline Dental problems & 16 & 23.5 \\
\hline Blood pressure & 15 & 12.3 \\
\hline Arteriosclerosis & 15 & 9.3 \\
\hline Smallpox & 11 & 3.4 \\
\hline Arthritis & 13 & 4.7 \\
\hline Trachoma & 9 & 3.4 \\
\hline Gout & 5 & 2.3 \\
\hline Meningitis & 5 & 4.8 \\
\hline Tuberculosis & 3 & 14.5 \\
\hline Gonorrhea & 7 & 12.5 \\
\hline Backache & 3 & 14.4 \\
\hline Heartburn & 10 & 20.3 \\
\hline Asthma & 8 & 11.4 \\
\hline Rheumatic fever & 9 & 2.4 \\
\hline Average & & 23.6 \\
\hline
\end{tabular}

TABLE 4: Local knowledge of the indigenous medicinal plant parts used for treatment of diseases in the Embobut Forest region ( $n=116)$.

\begin{tabular}{lcc}
\hline Plant parts used & Number of plants parts used (traditional healers) & Weighted local knowledge of plant parts used (\%) \\
\hline Roots & 42 & 67.2 \\
Stem & 29 & 48.6 \\
Branches & 8 & 43.7 \\
Leaf & 12 & 21.4 \\
Fruit & 9 & 8.3 \\
Bark & 7 & 6.6 \\
Bulb & 4 & 5.7 \\
Flowers & 5 & 6.9 \\
\hline
\end{tabular}

community members. The knowledge of medicine plants use was largely associated with common diseases in the area. However, the plants for the treatment of arteriosclerosis, meningitis, arthritis, trachoma, smallpox, rheumatic fever, and gout which are rare in the region were known only by the traditional healers and few local community members.

The study also established low levels of traditional knowledge of medicinal plant parts used. While knowledge of the use of root was wide among the local community members, the knowledge of the use of stem, branches, and leaf in management of disease was low among the local community members as well as the knowledge of the use of fruits, bark, bulb, and flowers. The discrepancies between knowledge and use indicate a possible erosion of local knowledge.

\section{Conclusions}

This study established that the traditional medicinal knowledge of medicinal plant use among Marakwets in Kenya was low or facing erosion. There is, therefore, an urgent need to document this information, as it is rapidly disappearing due to influence of western medicine and other reasons including sociocultural issues and overexploitation coupled with rapid deforestation. It is important to collect this information and develop a database of medicinal plants for future research and potential development of new drugs.

\section{Data Availability}

The data used to support the findings of this study are available from the corresponding author upon request. 


\section{Conflicts of Interest}

The author declares no conflicts of interest in publication of this manuscript.

\section{Acknowledgments}

The authors thank the members of Embobut community for their hospitality and receptivity during the fieldwork.

\section{Supplementary Materials}

Supplementary Table 1. Local identification, scientific name, common names, and families of the identified medicinal plant species in Embobut Forest based on local traditional knowledge $(n=116)$. (Supplementary Materials)

\section{References}

[1] A. K. Srivastava, Significance of Medicinal Plants in Human Life, Synthesis of Medicinal Agents from Plants, Elsevier, Amsterdam, Netherlands, 2018.

[2] R. W. Bussmann and D. Sharon, "Traditional medicinal plant use in Northern Peru: tracking two thousand years of healing culture," Journal of Ethnobiology and Ethnomedicine, vol. 2, p. 47, 2006.

[3] K. D. Kassaye, A. Amberbir, B. Getachew, and Y. Mussema, "A historical overview of traditional medicine practices and policy in Ethiopia," Ethiopian Journal of Health Development, vol. 20, pp. 127-134, 2006.

[4] B. Petrovska, "Historical review of medicinal plants' usage," Pharmacognosy Reviews, vol. 6, no. 11, p. 1, 2012.

[5] F. Jamshidi-Kia, Z. Lorigooini, and H. Amini-Khoei, "Medicinal plants: past history and future perspective," Journal of Herbmed Pharmacology, vol. 7, 2018.

[6] A. K. Shakya, "Medicinal plants: future source of new drugs," International Journal of Herbal Medicine, vol. 4, pp. 59-64, 2016.

[7] B.-E. Van Wyk and M. Wink, Medicinal Plants of the World, CABI, Wallingford, UK, 2017.

[8] Y. Huang, S. Ma, Y. Wang et al., "The role of traditional Chinese herbal medicines and bioactive ingredients on ion channels: a brief review and prospect," CNS \& Neurological Disorders-Drug Targets, vol. 18, no. 4, pp. 257-265, 2019.

[9] X. J. Wang, J. L. Ren, A. H. Zhang et al., "Novel applications of mass spectrometry-based metabolomics in herbal medicines and its active ingredients: current evidence," Mass Spectrometry Reviews, vol. 38, no. 4-5, pp. 380-402, 2019.

[10] M. N. K. Azam, M. A. Mannan, and M. N. Ahmed, "Medicinal plants used by the traditional medical practitioners of Barendra and Shamatat (Rajshahi \& Khulna division) region in Bangladesh for treatment of cardiovascular disorders," Journal of Medicinal Plants, vol. 2, pp. 9-14, 2014.

[11] J. Krupa, J. Sureshkumar, R. Silambarasan, K. Priyadarshini, and M. Ayyanar, "Integration of traditional herbal medicines among the indigenous communities in Thiruvarur district of Tamil Nadu, India," Journal of Ayurveda and Integrative Medicine, vol. 10, no. 1, pp. 32-37, 2018.

[12] D. Silveira, J. M. Prieto, M. M. Freitas, and A. L. Mazzari, Herbal Medicine and Public Healthcare: Current and Future Challenges, Natural Products as Source of Molecules with Therapeutic Potential, pp. 495-515, Springer, Berlin, Germany, 2018.
[13] S.-L. Chen, H. Yu, H.-M. Luo, Q. Wu, C.-F. Li, and A. Steinmetz, "Conservation and sustainable use of medicinal plants: problems, progress, and prospects," Chinese Medicine, vol. 11, p. 37, 2016.

[14] R. Rathore and M. Aditi, "Entrepreneurship development in medicinal and aromatic plants: prospects and challenges," International Journal of Economic Plants, vol. 5, no. 1, pp. 32-35, 2018.

[15] S. Sen and R. Chakraborty, "Toward the integration and advancement of herbal medicine: a focus on traditional Indian medicine," Botanics: Targets and Therapy, vol. 5, pp. 33-44, 2015.

[16] A. K. Dar, W. u. Hassan, A. H. Lone, A. Haji, N. Manzoor, and A. I. Mir, "Study to assess high demand and high commercial value medicinal plants of Jammu and Kashmir India-with special focus on routes of procurement and identification," International Journal of Research and Development in Pharmacy \& Life Sciences, vol. 6, no. 2, pp. 2576-2585, 2017.

[17] J. Amzat and O. Razum, Traditional Medicine in Africa, towards a Sociology of Health Discourse in Africa, Springer, Berlin, Germany, 2018.

[18] L. Zhang, H. Zhuang, Y. Zhang et al., "Plants for health: an ethnobotanical 25-year repeat survey of traditional medicine sold in a major marketplace in north-west Yunnan, China," Journal of Ethnopharmacology, vol. 224, pp. 119-125, 2018.

[19] E. C. Chukwuma, M. O. Soladoye, and R. T. Feyisola, “Traditional medicine and the future of medicinal plants in Nigeria," Journal of Medicinal Plants Studies, vol. 3, pp. 23-29, 2015.

[20] T. Van Andel, S. Van Onselen, B. Myren, A. Towns, and D. Quiroz, "The medicine from behind: the frequent use of enemas in western African traditional medicine," Journal of Ethnopharmacology, vol. 174, pp. 637-643, 2015.

[21] A. Zizka, A. Thiombiano, S. Dressler et al., "The vascular plant diversity of Burkina Faso (West Africa) - a quantitative analysis and implications for conservation," Journal of Ethnobiology and Ethnomedicine, vol. 70, no. 1, pp. 9-20, 2015.

[22] K. Arora, Forest Management by Andamanese Tribes, Indigenous Forest Management in the Andaman and Nicobar Islands, India, Springer, Berlin, Germany, 2018.

[23] A. Pieroni, A. Nedelcheva, and Y. Dogan, "Local knowledge of medicinal plants and wild food plants among Tatars and Romanians in Dobruja (South-East Romania)," Genetic Resources and Crop Evolution, vol. 62, no. 4, pp. 605-620, 2015.

[24] J. Blanco and S. M. Carrière, "Sharing local ecological knowledge as a human adaptation strategy to arid environments: evidence from an ethnobotany survey in Morocco," Journal of Arid Environments, vol. 127, pp. 30-43, 2016.

[25] J. Kimondo, J. Miaron, P. Mutai, and P. Njogu, "Ethnobotanical survey of food and medicinal plants of the Ilkisonko Maasai community in Kenya," Journal of Ethnopharmacology, vol. 175, pp. 463-469, 2015.

[26] M. S. Sosef, G. Dauby, A. Blach-Overgaard et al., "Exploring the floristic diversity of tropical Africa," BMC Biology, vol. 15, p. 15, 2017.

[27] T. Ulian, M. Sacandé, A. Hudson, and E. Mattana, "Conservation of indigenous plants to support community livelihoods: the MGU-useful plants project," Journal of Environmental Planning and Management, vol. 60, no. 4, pp. 668-683, 2017.

[28] M. Vellend, L. Baeten, A. Becker-Scarpitta et al., "Plant biodiversity change across scales during the Anthropocene," Annual Review of Plant Biology, vol. 68, no. 1, pp. 563-586, 2017. 
[29] V. Droissart, G. Dauby, O. J. Hardy et al., "Beyond trees: biogeographical regionalization of tropical Africa," Journal of Biogeography, vol. 45, no. 5, pp. 1153-1167, 2018.

[30] G. Kigen, Z. Kamuren, E. Njiru, B. Wanjohi, and W. Kipkore, "Ethnomedical survey of the plants used by traditional healers in Narok County, Kenya," Evidence-Based Complementary and Alternative Medicine, vol. 2019, Article ID 8976937, 8 pages, 2019.

[31] M. Moyo, A. O. Aremu, and J. Van Staden, "Medicinal plants: an invaluable, dwindling resource in sub-Saharan Africa," Journal of Ethnopharmacology, vol. 174, pp. 595-606, 2015.

[32] N. Mukungu, K. Abuga, F. Okalebo, R. Ingwela, and J. Mwangi, "Medicinal plants used for management of malaria among the Luhya community of Kakamega East sub-county, Kenya," Journal of Ethnopharmacology, vol. 194, pp. 98-107, 2016.

[33] P. Tugume, E. K. Kakudidi, M. Buyinza et al., "Ethnobotanical survey of medicinal plant species used by communities around Mabira Central Forest Reserve, Uganda," Journal of Ethnobiology and Ethnomedicine, vol. 12, p. 5, 2016.

[34] P. M. Kariuki, C. M. Onyango, C. W. Lukhoba, and J. T. Njoka, "The role of indigenous knowledge on use and conservation of wild medicinal food plants in Loita subcounty, Narok County," Asian Journal of Agricultural Extension, Economics \& Sociology, vol. 28, no. 2, pp. 1-9, 2018.

[35] M. Phumthum, K. Srithi, A. Inta et al., "Ethnomedicinal plant diversity in Thailand," Journal of Ethnopharmacology, vol. 214, pp. 90-98, 2018.

[36] G. K. Kigen, H. K. Ronoh, W. K. Kipkore, and J. K. Rotich, "Current trends of traditional herbal medicine practice in Kenya: a review," African Journal of Pharmacology and Therapeutics, vol. 2, 2013.

[37] O. Amuka, A. K. Machocho, P. K. Mbugua, and P. O. Okemo, "Ethnobotanical survey of selected medicinal plants used by the ogiek communities in Kenya against Microbial Infections," Ethnobotany Research and Applications, vol. 12, pp. 627-641, 2014.

[38] G. Okemo, F. Some, and J. Kibosia, "Ethnomedicinal plants traditionally used by the keiyo community in Elgeyo Marakwet County, Kenya," Journal of Biodiversity, Bioprospecting and Development, vol. 1, no. 3, p. 132, 2014.

[39] W. Kipkore, B. Wanjohi, H. Rono, and G. Kigen, "A study of the medicinal plants used by the Marakwet Community in Kenya," Journal of Ethnobiology and Ethnomedicine, vol. 10, no. 1, p. 24, 2014.

[40] L. N. Kamau, M. P. Mbaabu, J. M. Mbaria, G. P. Karuri, and S. G. Kiama, "Knowledge and demand for medicinal plants used in the treatment and management of diabetes in Nyeri County, Kenya," Journal of Ethnopharmacology, vol. 189, pp. 218-229, 2016.

[41] G. Kigen, A. Maritim, F. Some et al., "Ethnopharmacological survey of the medicinal plants used in Tindiret, Nandi County, Kenya," African Journal of Traditional, Complementary and Alternative Medicines, vol. 13, no. 3, pp. 156-168, 2016.

[42] E. Odongo, N. Mungai, P. Mutai, E. Karumi, J. Mwangi, and J. Omale, "Ethnobotanical survey of the medicinal plants used in Kakamega County, western Kenya," Applied Medical Research, vol. 4, no. 1, p. 22, 2018.

[43] B. Rotich, "Forest conservation and utilization in Embobut, Cherangani hills, Kenya," International Journal of Natural Resource Ecology and Management, vol. 4, no. 1, p. 7, 2019.

[44] J. Omona, "Sampling in qualitative research: improving the quality of research outcomes in higher education," Makerere Journal of Higher Education, vol. 4, pp. 169-185, 2013.
[45] I. Etikan, S. A. Musa, and R. S. Alkassim, "Comparison of convenience sampling and purposive sampling," American Journal of Theoretical and Applied Statistics, vol. 5, no. 1, pp. 1-4, 2016.

[46] K. S. Taber, "The use of cronbach's alpha when developing and reporting research instruments in science education," Research in Science Education, vol. 48, no. 6, pp. 1273-1296, 2018.

[47] D. J. Gafna, K. Dolos, I. O. Mahiri, J. G. Mahiri, and J. A. Obando, "Diversity of medicinal plants and anthropogenic threats in the Samburu central sub-county of Kenya," African Journal of Traditional, Complementary and Alternative Medicines, vol. 14, pp. 72-79, 2017.

[48] C. J. Rotich, G. O. Oduor, E. W. Njagi et al., "The utilisation and conservation of indigenous medicinal plants in selected areas in Baringo County, Kenya," Master thesis, Kenyatta University, Nairobi, Kenya, 2016.

[49] G. Kewessa, T. Abebe, and A. Demissie, "Indigenous Knowledge on the use and management of medicinal trees and shrubs in Dale district, Sidama zone, Southern Ethiopia," Ethnobotany Research and Applications, vol. 14, pp. 171-182, 2015.

[50] M. K. Mathibela, B. A. Egan, H. J. Du Plessis, and M. J. Potgieter, "Socio-cultural profile of Bapedi traditional healers as indigenous knowledge custodians and conservation partners in the Blouberg area, Limpopo Province, South Africa," Journal of Ethnobiology and Ethnomedicine, vol. 11, p. 49, 2015.

[51] F. Ijaz, Z. Iqbal, I. U. Rahman et al., "Investigation of traditional medicinal floral knowledge of Sarban Hills, Abbottabad, KP, Pakistan," Journal of Ethnopharmacology, vol. 179, pp. 208-233, 2016.

[52] S. F. H. Syamsiah, A. Mu'nisa, and O. Jumadi, "Study on medicinal plants used by the ethnic Mamuju in West Sulawesi, Indonesia," Journal of Tropical Crop Science, vol. 3, 2016.

[53] R. Tang and M. Gavin, "A classification of threats to traditional ecological knowledge and conservation responses," Conservation and Society, vol. 14, no. 1, p. 57, 2016.

[54] A. Bouyahya, J. Abrini, A. Et-Touys, Y. Bakri, and N. Dakka, "Indigenous knowledge of the use of medicinal plants in the North-West of Morocco and their biological activities," European Journal of Integrative Medicine, vol. 13, pp. 9-25, 2017.

[55] A. Sharma, H. Singh, and N. Kumar, "Studies on traditional knowledge of medicinal flora and its contribution to livelihood enhancement in the doon-valley, Uttrakhand (India)," International Journal of Life-Sciences Scientific Research, vol. 3, pp. 951-960, 2017. 